\title{
What comes next? \\ The operator theory as an operationalisation of the Teilhardian view on cosmogenesis
}

Hub Zwart

H. Zwart (2016) What comes next? The operator theory as an operationalisation of the Teilhardian view on cosmogenesis. In: G. Jagers (ed.) Evolution and Transitions in Complexity: the science of hierarchical organisation in nature. Dordrecht: Springer, 253258. DOI 10.1007/978-3-319-43802-3.

\section{The Scala naturae revisited}

The Scala naturae concept, - i.e. the idea that certain levels of complexity can be discerned in nature, and that the history of life and evolution is characterised by a basic tendency towards increased complexity -, has been vehemently challenged and discarded as "romantic", "unscientific" or "pre-scientific" by a large number of opponents, most eloquently perhaps by Stephen Jay Gould in his book Ontogeny and Phylogeny (1977). The very idea of a drive towards complexity is often regarded as belonging to a metaphysical worldview, and as incompatible with a modern biological approach. Many see it as a remnant of Naturphilosophie, inspired by philosophers such as Hegel and Schelling and predating what Gaston Bachelard (1938) has referred to as the "epistemological rupture", i.e. the birth of real (detached, quantitative, experimental) science. And yet, up to the present, the Scala naturae concept proves to be a remarkably stubborn and recurring idea, resurging every now and then as a kind of "return of the repressed", and as a philosophical, but also as a biological conception.

Several continental philosophers (from Hegel, Schopenhauer and Nietzsche up to Binswanger and Sloterdijk) have thematised this persistent drive towards increased complexity in terms of the vertical dimension of existence, a dimension which is most obviously noticeable in humans. Human beings, these authors claim, not only strive for continuation, propagation and reproduction (the horizontal dimension), but also for optimisation and self-improvement (both individually and collectively), through exercise, experimentation and technology. ${ }^{1}$ We human beings are regarded as unhappy animals par excellence, aiming to surpass and transcend ourselves, frantically trying to attain a higher level of existence. At the same time, this human tendency can be regarded as an exemplification (or intensification) of a basic drive discernible in

\footnotetext{
${ }^{1}$ See for instance Sloterdijk (2009) for a recent recapitulation of this view.
} 
nature as such: the so-called "will to power" (Nietzsche), the drive to surpass and grow; the desire to experience a dramatic transformation, a leap-like change. And while Schopenhauer and Nietzsche regarded it as a blind process more or less, Hegel has argued that a certain logic or even dialectics can be discerned in it, so that we are not only able to flesh out a reconstruction of the past and a diagnostics of the present, but also a prognostics of the emerging future (what will be the next unfolding step?). One could argue, moreover, that a kind of Hegelian dialectical dynamics is even reflected in the history of the scala naturae idea as such. It sets off as a static vision ('thesis'), provoking an antithetical denial in modernity (i.e. the claim that there is no such thing as increased complexity in nature); but finally giving rise to a dynamical view of increasing complexity as the basic narrative of evolution (the 'synthesis'), for instance in the form of the operator theory.

Against the backdrop of this polemical debate between critics and adherents, - which to a certain extent tended to coincide with a debate between disciplines, namely biology and (continental) philosophy -, the operator hierarchy constitutes a provocative gesture. It aims to rehabilitate the scala naturae idea by recasting it in scientific and biological terms, in close dialogue with insights from contemporary research fields. From this perspective one could argue that the operator theory seems congruent with an important precedent, namely the view of Teilhard de Chardin, a Jesuit priest, but also a paleo-anthropologist, who contributed to the discovery of Homo erectus fossils in China in the 1920s and whose views were already briefly discussed above, notably because of his influence on authors such as Stikker (1992). In the next section I will summarise his views, notably building on his book The Phenomenon of Man, published shortly after his death (in 1955).

\section{Evolution becoming conscious of itself}

In the history of the universe, Teilhard (1955) argues, a continuous process towards increased complexity can indeed be discerned. In the history of planet earth, as a theatre of evolution, we find this reflected in the development of a series of subsequent layers of increasing complexity: from the (abiotic) geosphere via the (living) biosphere up to the man-made noosphere (i.e. the evolving layer of intelligence and technology and their networks and products, relentlessly and increasingly absorbing and reorganising both the geosphere and biosphere). Entities of greater complexity emerge from basic building blocks (true natural units), as was already briefly explained elsewhere in this volume, so that radiation gives rise to atoms, atoms to molecules, molecules (via 
crystals and polymers) ${ }^{2}$ to biomolecules (biopolymers) and living cells (with their "exceptional aptitude to branch out into new forms", giving rise to a diffuse super-organism, a living film, p. 94), and from single cells to eukaryotic organisms.

Teilhard's starting point is the claim that evolution indeed displays an orientation, an axis, a line of progress, a direction, namely towards increased complexity, towards self-consciousness and self-directedness. In the laboratory of the universe, a trend towards synthesis and sublimation can be discerned. This notably applies to life, a decidedly "experimental" form of reality (p. 77). Life is a process of synthetic sublimation which, via endless permutations and combinations of basic units, gives rise to a mega-synthesis of complex forms (p. 106). In other words, life not only propagates, but ascends as well (p. 107). In the course of evolution, moreover, living entities are increasingly able to consciously co-determine the conditions of their own existence. And this applies in a rather outspoken manner to the most recently evolved species, namely humans.

Teilhard sees humans beings as "evolution becoming conscious of itself" (p. 181). Evolution is basically a process of "sublimation" (p. 106), transposing physiology into culture, culminating in a process of cerebralisation and, ultimately, of self-conscious self-directedness. In Homo sapiens, the deluge of cerebralisation gave rise to completely new forms of experimentation via technology, language, science and art. Teilhard is well aware that in mainstream biological discourse such claims are encountered with disavowal, but for Teilhard, "sublimation" constitutes an undeniable evolutionary dynamics.

Currently, Teilhard argues, we find ourselves on the verge of a rather decisive turn. Due to global human activity, a new layer has emerged, over and above the biosphere, namely the noosphere, which literally means the "thinking layer" (derived from the Greek term voũs: i.e. 'mind' or 'intellect') which, besides noetic activities, also involves noetic products (technologies, devices, culture, infrastructures, industrial plants, airplanes, and so on). In other words, the noosphere is evolving into a planetary network of advanced technologies and global collaborative circuits. Humans are obviously animals, and yet we represent a discontinuity, a leap, a crisis, a metamorphosis, an awakening, giving rise to the emergence of the noosphere, the thinking layer, relentlessly transforming and absorbing the biosphere. Indeed, the noosphere represents a conscious reshaping of the world, an epochal transformation affecting the entire planet.

Teilhard emphatically stresses that this does not does imply an anthropocentric view, seeing humans as the pinacle of evolution (as was the case in the static scala naturae view). Rather, we humans are pushed along by this development ourselves, we are subject to a relentless process of hominization and collectivization, culminating in the emergence of a global 'We': a planetary

\footnotetext{
${ }^{2}$ Teilhard refers to polymerisation as an emerging "work of "synthesis" (p. 70)
} 
network of thought and interaction. Indeed, Teilhard has been credited, by Garreau (2005) and others, with predicting the internet: WWWW as a global noetic structure. For Teilhard, humans are a bridge. We ourselves are pushed forward by the inevitable planetisation of the noosphere. A turn of profound importance is taking place throughout the world, and we are only beginning to realise its true dimensions. We have already entered a different world: more mobile, fluid and migratory than the world of agriculture. "The future will decide what the best name is to describe the era we are entering", Teilhard tells us (p. 214), but he clearly seems to be pointing at what we nowadays often refer to as the Anthropocene.

But this does not mean that we humans are in charge. Rather, a sense of disquiet is coming over us. The emerging situation is without precedent in the history of life and therefore, more than ever before, we experience a fundamental existential anguish. An enormous challenge is looming up in front of us. Humans are not the centre of the universe, but rather a vector pointing towards an emerging, planetary unification of the world (p. 224). We are waking up to the fact that the planet itself is now becoming thoroughly humanised and technified: a process of intellectual and technological collectivisation and convergence, resulting in the emergence of a global humanity, empowered to initiate collective action. Somehow, our uneasiness must be transformed into active thinking, a combination of foresight and coordinated action. It is only by becoming aware of the basic dynamics of the evolutionary process that we can we hope to play a constructive rather than a disruptive role. We must acknowledge that Darwinian evolution is becoming eclipsed by conscious transformation, by an active metamorphosis of the planet, a drastic reorganisation of the evolutionary process, and the noosphere is already producing a new wave of genetically modified organisms, which Teilhard refers to as neo-life (p. 250). Increasingly, the noosphere will reorganise natural selection, via a computer-based, electronic selfconsciousness, which increasingly will be superimposed on Darwinian heredity (cf. Zwart 2009; Zwart 2012).

\section{A Teilhardian view of the operator theory}

This calls for a drastic reorganisation of scientific research itself as well, Teilhard argues, which has to be transformed into a kind of planetary organisation, allowing for global teamwork. Notably in science, individuality must give way to technology-based hyper-reflection and hyperpersonalisation (p. 259). Individual egos will dissolve into a distributed, super-centralised network of thought (p. 262). And this will affect the role and fate of philosophy as well, which should no 
longer be regarded as a solitary calling, but rather as a collective endeavour, as distributed, transdisciplinary form of reflection, involving multiple voices working in various places, but based on a clear awareness of the dynamics and the direction of the processes involved, so that it becomes possible to identify and consciously shape the next stage.

The operator theory is an effort to empower us to achieve exactly this. Whereas Teilhard was convinced that we are heading for the Omega Point (a theological, eschatological concept), ${ }^{3}$ the operator theory rather predicts that the next stage will entail the emergence (already unfolding) of a noospheric global network of robotics and ICT, increasingly marginalising and replacing us.

Bachelard, Gaston (1938) La Formation de l'esprit scientifique: Contribution à une psychanalyse de la connaissance objective. Paris : Vrin.

Garreau, Joel (2005) Radical evolution: the promise and peril of enhancing our minds, our bodies - and what it means to be human. New York: Broadway Books.

Gould, Stephen Jay (1977). Ontogeny and Phylogeny. Cambridge: Belknap Press / Harvard University Press. Sloterdijk, Peter (2009). Du musst dein Leben ändern: Über Anthropotecbnik. Frankfurt am Main: Suhrkamp. Stikker Allard (1992) The transformation factor. Towards and ecological consciousness. Element. Rockport, USA. Teilhard de Chardin, Pierre (1955) The Phenomenon of Man. New York: Harper [Le phénomène bumain. Paris: Editions du Seuil.]

Teilhard de Chardin, Pierre (1957) Le Milieu Divin: Essai de vie intérieure. Paris : Editions du Seuil. Zwart Hub (2009) From utopia to science: challenges of personalised genomics information for health management and health enhancement. Medicine Studies, 1 (2), 155-166.

Zwart Hub (2012) On decoding and rewriting genomes: A psychoanalytical reading of a scientific revolution. Medicine, Healthcare and Philosophy: a European Journal. 15 (3), 337- 346.

\footnotetext{
${ }^{3}$ More fully elaborated elsewhere (Teilhard de Chardin 1957) as the 'pleroma', the fullness of time.
} 